\title{
A New Antenna with Dual Band-Notched Function by Shorting Pin and S-shaped Coupling Element
}

\author{
M. Akbari, R. Movahedinia, A. R. Sebak, \\ Electrical and Computer Department, Concordia \\ University, Montreal, Quebec H3G 1M8, Canada \\ akbari.telecom@gmail.com,mo_akba@encs.concordia.ca \\ N. Rojhani \\ Young Researchers and Elite club, South Tehran Branch, \\ Islamic Azad University, Tehran, Iran
}

\author{
Saman Zarbakhsh \\ Young Researchers and Elite club, Central Tehran \\ Branch, Islamic Azad University, Tehran, Iran \\ Vijay Devabhaktuni, Senior Member, IEEE \\ Electrical and Computer Department, the University of \\ Toledo Toledo, $\mathrm{OH} 43606$ \\ Vijay.Devabhaktuni@utoledo.edu
}

\begin{abstract}
UWB antenna with dual bandnotch function is presented. The antenna consists of a square patch and a partial ground plane. For expanding the impedance bandwidth, H-shaped slot on the ground plane is etched. Also, to obtain two notched bands, S-shaped coupling element and an inverted L-shaped arm ended up a shorting pin are utilized. The antenna has a compact size of $15 \times 22 \mathrm{~mm}^{2}$ which has been printed on an Fr4 substrate. Moreover, the proposed antenna has been successfully fabricated and measured, indicating broadband matched impedance (2.6-11.4 GHz, VSWR $\leqslant 2$ ) and dual bandnotched (3.2-4 GHz and 5.1-6.1 GHz) respectively.
\end{abstract}

Index Terms-UWB, Antenna, Notched Band, Shorting pin.

\section{INTRODUCTION}

Commercial ultra-wideband (UWB) systems require compact, cheap antennas with omnidirectional patterns and extended bandwidth. It is a popular fact that monopole antennas present really attractive physical features, namely simple structure, small size and low cost. Because of all these interesting characteristics, planar monopoles are quite appealing to be used in emerging UWB applications, and rising research activity is being focused on them. In UWB communication systems, one of main subjects is the design of a compact antenna whilst providing wideband characteristic over the all operating frequency band. Consequently, an enormous number of microstrip antennas with different structures have been experimentally characterized which patch of this type of reported antennas has different shapes such as rectangular, disc, triangle and oval forms [1-5], [17]. There are many techniques on patch, feed line and ground structure to enhance the impedance bandwidth and access to UWB bandwidth [6-7]. The frequency range for UWB systems between 3.1 and 10.6 $\mathrm{GHz}$ will end up interference to the existing wireless communication systems, such as the wireless local area network (WLAN) for IEEE 802.11a operating in 5.15-5.35 $\mathrm{GHz}$ and $5.725-5.825 \mathrm{GHz}$ bands, therefore the UWB antenna with a band-stop performance is needful. Newly, to create the frequency band-notch function, modified planar monopoles have been recently presented [8-12]. According to it, the antenna presented in [8] has been designed by embedding a pair of T-shaped stubs in the radiation patch and a modified Gslot defected ground structure in the feeding line, [9-10] use traditional method of U-shaped slot on the patch, and [11] applies T-shaped stub embedded in the square slot of the radiation patch and a pair of U-shaped parasitic strips beside the feed line. At the end of paper using Table 2, the antenna is compared to references [8-11], [17].

\section{ANTENNA DESIGN AND RESULTS}

The configuration and photo of the fabricated antenna are shown in figure 1, which has been printed on an FR4 substrate with thickness $1 \mathrm{~mm}$ and permittivity 4.4 . To connect a $50-\Omega$ SMA connector for signal transmission, the width of the microstrip feedline, Wf, is fixed at $1.9 \mathrm{~mm}$. The basic antenna structure contains a square patch, a feedline, and a partial ground plane. On the other side of the substrate, a conducting ground plane with width Wsub and length Lgnd is situated. The ground plane with an $\mathrm{H}$-shape plays an important role in the broadband characteristics of this antenna, because it can adjust the electromagnetic coupling effects between the patch and the ground plane, and improve its impedance bandwidth without any cost of size or expense. To achieve two notched bands, two diverse techniques have been used, the former S-shaped coupling element on the back side and the latter an inverted Lshaped arm ended up a shorting pin. 


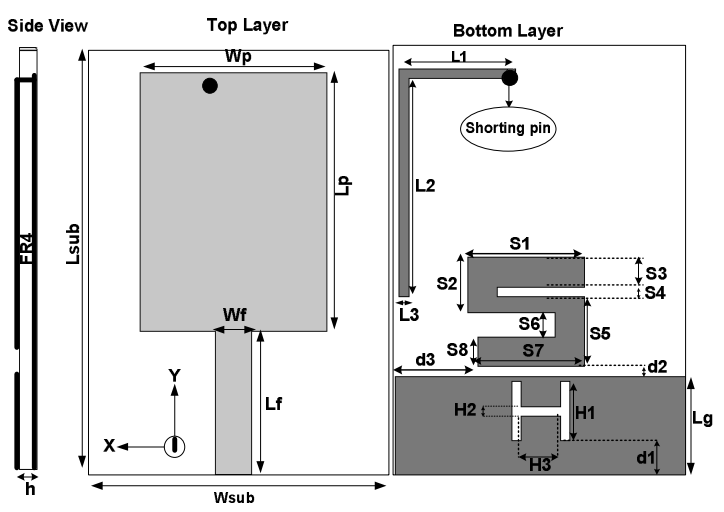

(a)

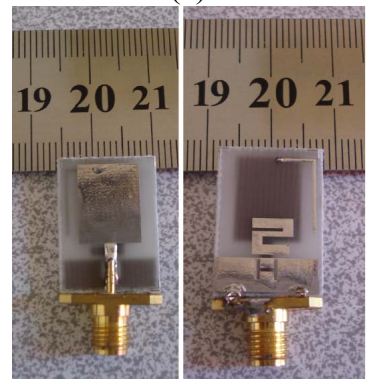

(b)

Fig. 1. Geometery (a) and photo (b) of the fabricated antenna

Table 1. Optimal Dimensions of the Antenna

\begin{tabular}{|c|c|c|c|c|c|c|c|}
\hline Prm & (mm) & Prm & $(\mathbf{m m})$ & Prm. & (mm) & Prm. & (mm) \\
\hline Lsub & 22 & Wsub & 15 & Wp & 10 & Lp & 13.5 \\
\hline Wf & 1.9 & Lf & 7.5 & Lg & 5 & L1 & 6 \\
\hline L2 & 11 & L3 & 0.5 & S1 & 6 & S2 & 2.8 \\
\hline S3 & 1.5 & S4 & 0.5 & S5 & 3.5 & S6 & 1.2 \\
\hline S7 & 5.5 & S8 & 1.5 & H1 & 3 & H2 & 0.5 \\
\hline H3 & 2 & d1 & 1.75 & d2 & 0.5 & d3 & 4.25 \\
\hline
\end{tabular}

\section{ANTENNA PERFORMANCE AND DISCUSSION}

Computation of the dispersion when the antenna radiates a pulse signal is also of interest. The transmit transfer functions of the antennas were used to compute the radiated pulse in different directions when a reference signal was applied at the antenna input. This signal should present an UWB spectrum covering the antenna bandwidth and particularly the FCC mask from 3.1 to $10.6 \mathrm{GHz}$. It is shown in figure 2 that an acceptable approximation to a FCC mask compliant pulse can be obtained with a Gaussian seventh derivative. This pulse is represented in the time domain by:

$$
\begin{aligned}
& G(t)=A \cdot \exp \left(\frac{-t^{2}}{2 \delta^{2}}\right) \\
& G^{n}(t)=\frac{d^{n} G}{d t^{n}} \\
& =(-1)^{n} \frac{1}{(\sqrt{2} \delta)^{2}} \cdot H_{n}\left(\frac{t}{\sqrt{2} \delta}\right) \cdot G(t) \\
& H_{7}(t)=128 t^{7}-1344 t^{5}+3360 t^{3}-1680 t
\end{aligned}
$$

This signal and its spectrum are represented in figure 2. The pulse bandwidth is exactly into mask desired.

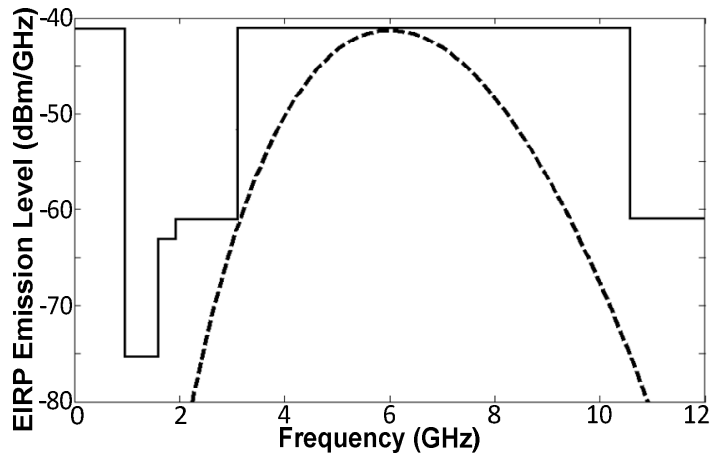

Fig. 2. Power Spectrum Density compared to FCC mask

Luckily, after drawing various Gaussian pulses from the first to eighth derivative, it was obtained that the best pulse for covering FCC mask can be the seventh derivative. Besides, with a bit tolerance, the sixth and eighth derivative are acceptable. In telecommunications systems, the correlation between the transmitted (TX) and received (RX) signals is evaluated using the fidelity factor (4):

$$
F=\max _{\tau}\left|\frac{\int_{-\infty}^{+\infty} S(t) r(t-\tau) d t}{\sqrt{\int_{-\infty}^{+\infty} S(t)^{2} \cdot \int_{-\infty}^{+\infty} r(t)^{2} d t}}\right|
$$

Where $\mathrm{S}(\mathrm{t})$ and $\mathrm{r}(\mathrm{t})$ are the TX and RX signals, respectively.

For impulse radio in UWB communications, it is necessary to have a high degree of correlation between the TX and RX signals to avoid losing the modulated information. However, for most other telecommunication systems, the fidelity parameter is not that relevant. In order to evaluate the pulse transmission characteristics of the antenna in the case of without notch, two configurations (side-by-side and face-toface orientations) were chosen. The transmitting and receiving antennas were placed in a distance $\mathrm{d}=25 \mathrm{~cm}$ from each other [14]. As shown in figures 3, although the received pulses in each of two orientations are broadened, a relatively good similarity exists between the RX and TX pulses. Using (4), the fidelity factor for the face-to-face and side-by-side configurations was obtained equal to 0.92 and 0.96 , respectively. These values for the fidelity factor show that the antenna imposes negligible effects on the transmitted pulses. The pulse transmission results are obtained using CST [15]. Phase of S21 for the face to face and side by side orientations are also illustrated in figure 4 . As previously expected, the plot shows a linear variation of phase in the total operating band except notched bands. 


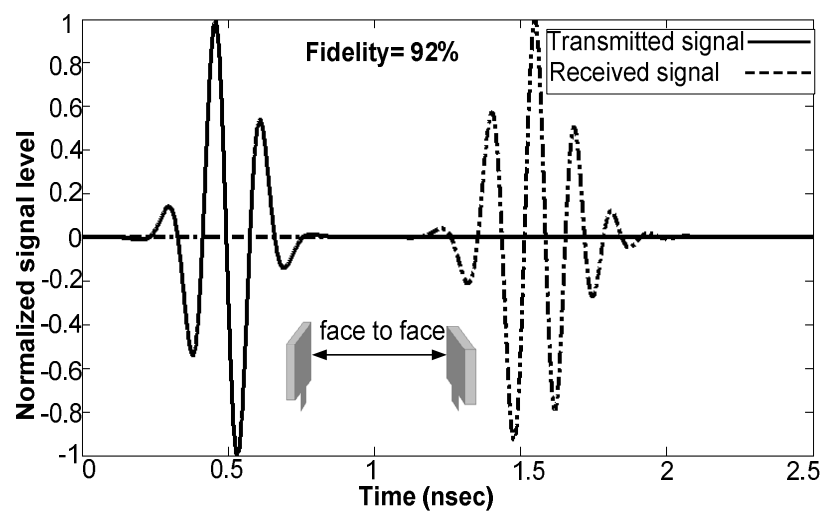

(a)

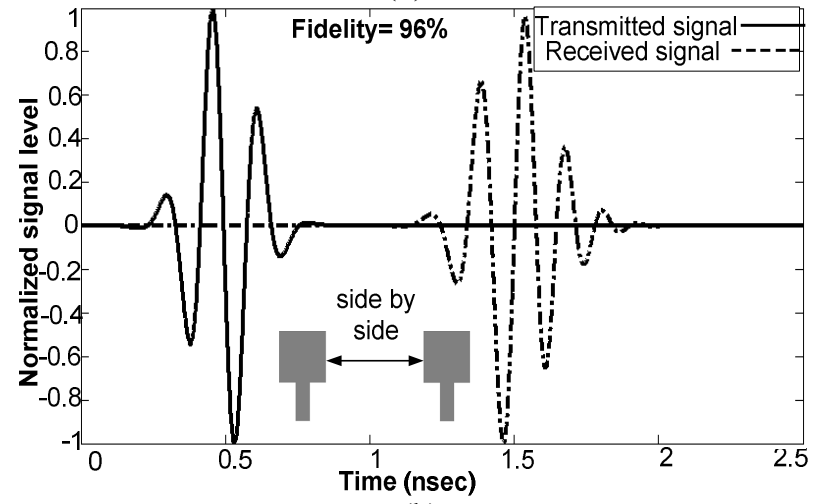

(b)

Fig. 3. Transmitted and received pulses in time domain for a UWB link with identical antennas without notches in (a) face to face and (b) side by side orientations

The parameters of the antenna are studied by changing one parameter at a time and fixing the others. The simulated results are achieved using the Ansoft simulation software highfrequency structure simulator [16]. The optimal dimensions of the designed antenna are demonstrated in Table1. Figures 5 and 6 exhibit simulated VSWR for the various structures of monopole antenna. With the use of $\mathrm{H}$-shaped slot the bandwidth can be increased markedly, creating the third resonance at $10 \mathrm{GHz}$, expanding the bandwidth by $10.8 \mathrm{GHz}$. Meanwhile, S-shaped coupling element on the back side not only can generate a notched band at center frequency $5.5 \mathrm{GHz}$, but also can rise the bandwidth on the upper band approximately $0.8 \mathrm{GHz}$. From figure 6 is seen that an inverted L-shaped arm ended up a shorting pin have effect on notched band at center frequency $3.5 \mathrm{GHz}$ while the S-shaped coupling element can produce a stop band at center frequency $5.5 \mathrm{GHz}$ to filter WLAN and WiMAX bands respectively. Besides, it is found out that both notches are independent than each other, it means that they have no effect on each other. As depicted in figure 7, parameter S7 has a noticeable influence on frequency shifting. According to it, with increasing length of S7 the center frequency is decreased regularly in a way that with rising $0.5 \mathrm{~mm}$ in length $\mathrm{S} 7$ the centre frequency of notched band is reduced approximately $0.5 \mathrm{GHz}$. The best value S7 for covering 5.15 to 5.825 corresponds to $5.5 \mathrm{~mm}$.

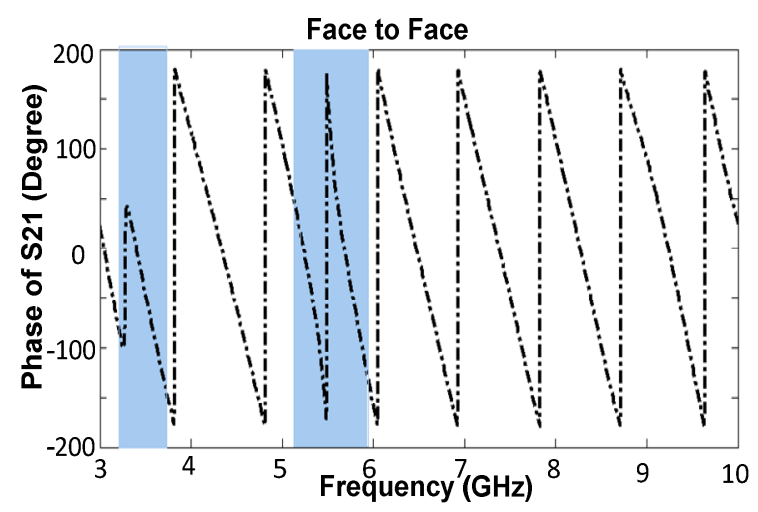

(a)

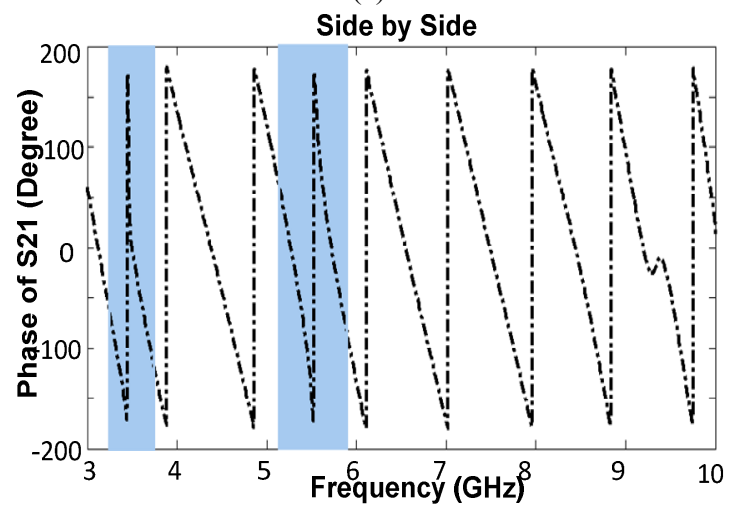

(b)

Fig. 4. Simulated phase S21 with a pair of identical antennas for (a) face to face (b) side by side orientations.

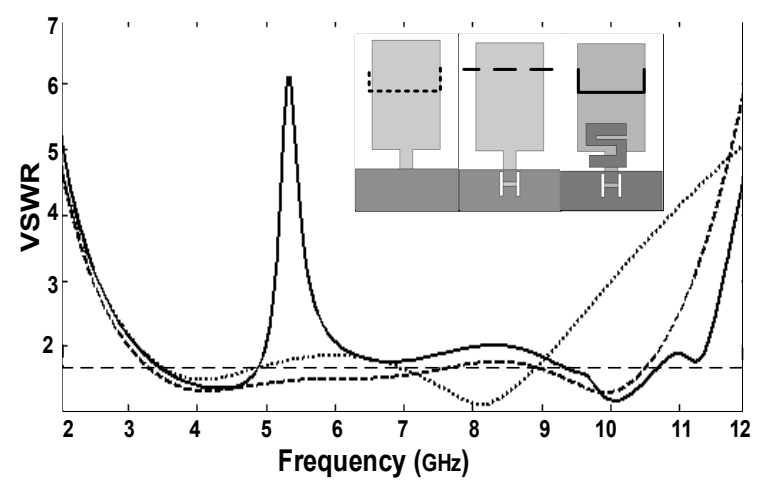

Fig. 5. Simulated VSWR for the various structures of monopole antenna showing wide impedance bandwidth

As said above, in this study to generate the band-stop performance on WiMAX band with center frequency $3.5 \mathrm{GHz}$, an inverted L-shaped arm, with length of L1+L2, connected to a shorting pin is used. The simulated VSWR curves with different values L2 are plotted in figure 8. When the length L2 increases gradually the center frequency of the notched band is diminished steadily. Thus, the optimized L2 is $11 \mathrm{~mm}$. From these results, it can be concluded that the notch frequencies are controllable by changing the lengths S7 and L2. To understand more clearly, figure 9 is used showing the simulated current distributions on both the sides of the antenna. 


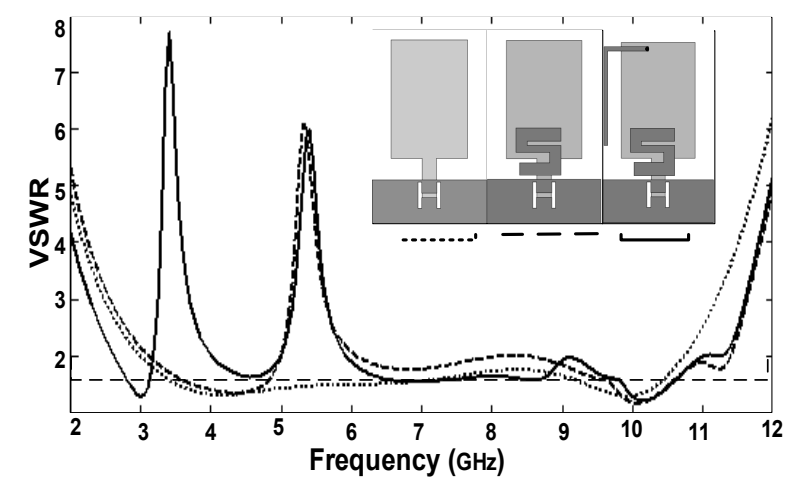

Fig. 6. Simulated VSWR for the various structures of monopole antenna showing notched bands

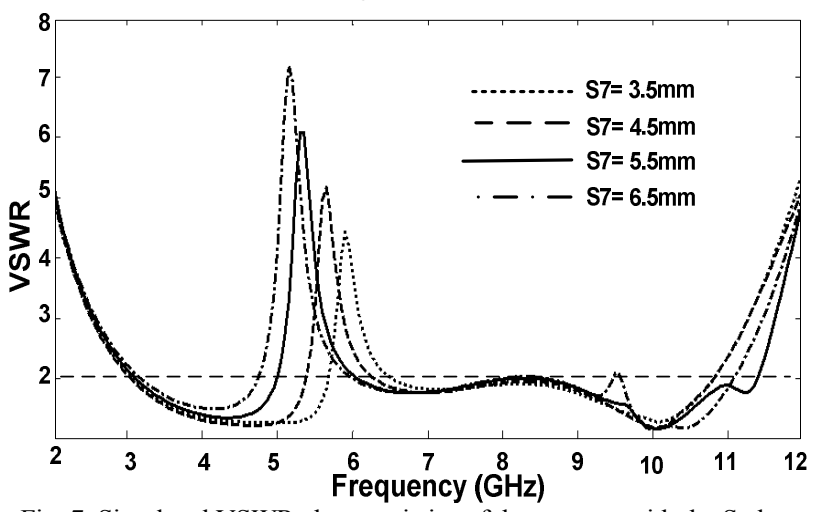

Fig. 7. Simulated VSWR characteristics of the antenna with the S-shaped coupling element with different values S7

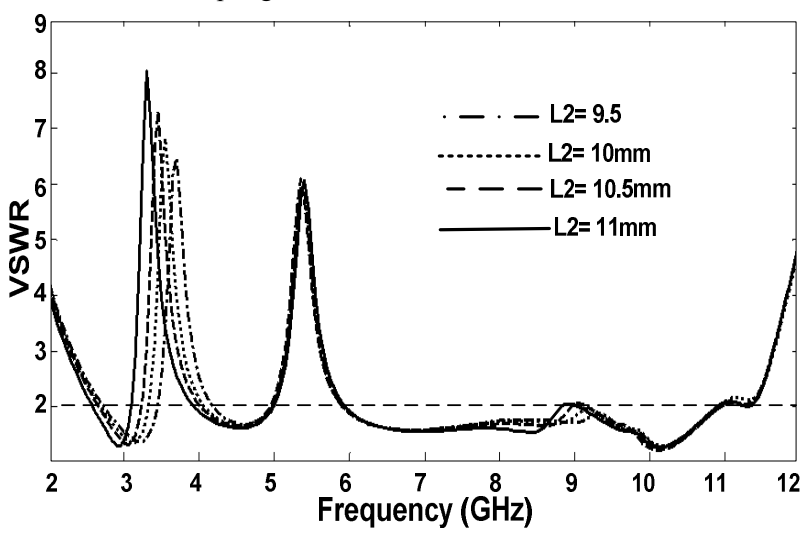

Fig. 8. Simulated VSWR characteristics of the antenna with an inverted Lshaped arm ended up shorting pin with different values L2

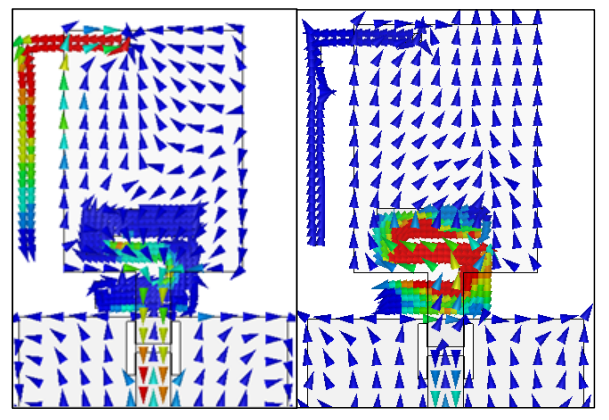

(a)

(b)

Fig. 9. Simulated surface current distributions (a) on the L-shaped arm ended up shorting pin at $3.5 \mathrm{GHz}$ and (b) on S-shaped coupling element at $5.5 \mathrm{GHz}$
It can be observed in figure 9(a), by using an inverted Lshaped arm ended up shorting pin, the current is concentrated on the arm at $3.5 \mathrm{GHz}$. Further point that, the current direction on the edge of patch is opposite, 180 degree phase difference, to its direction on L-shaped arm. Figure 9(b) depicts the current distribution at $5.5 \mathrm{GHz}$ in a way that most of the current is seen on S-shaped coupling element indicating its effect in creating the second notched band at centre frequency $5.5 \mathrm{GHz}$. Figure 10 shows the measured and simulated VSWR characteristics of the proposed antenna. The fabricated antenna can cover the frequency band of 2.6 to over $11.4 \mathrm{GHz}$. The designed antenna has a small size of $15 \times 22 \mathrm{~mm}^{2}$ while showing the band rejection performance in the frequency bands of 3.2 up to 4 $\mathrm{GHz}$ and 5.1 to $6.1 \mathrm{GHz}$ respectively. As displayed in figure 10 , there is a discrepancy between measured result and the simulated data, it is more likely because of the effect of the SMA port. Figure 11 illustrates the simulated radiation patterns constituting the co-polarization and cross-polarization in the $\mathrm{H}$ plane ( $\mathrm{x}-\mathrm{z}$ plane) and E-plane ( $\mathrm{y}-\mathrm{z}$ plane). It can be seen that the radiation patterns in $\mathrm{x}-\mathrm{z}$ plane are about omnidirectional for the two frequencies while radiation pattern in $y-z$ plane are nearly directional.

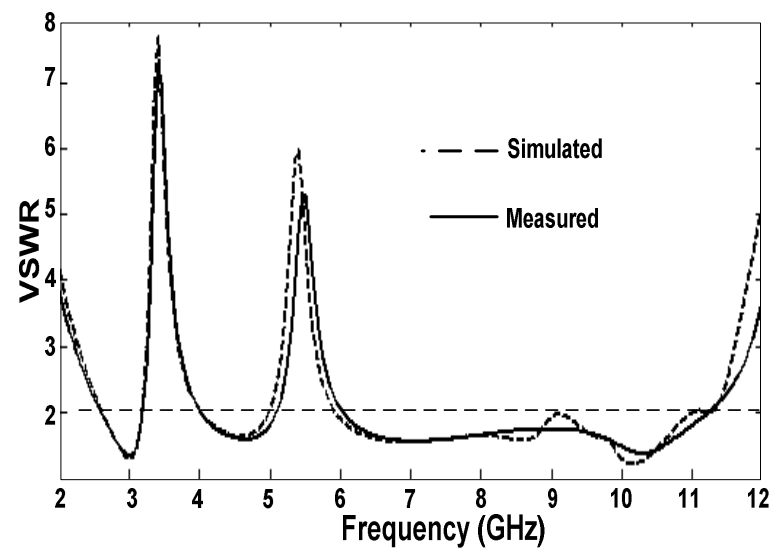

Fig. 10. Measured and simulated VSWR characteristics for the proposed antenna

The comparisons for several different dual-notched-band UWB antennas are illustrated in Table 2. Compared to [8-11], the proposed UWB antenna with dual notched bands in terms of size and bandwidth has better characteristics. Further point, the used techniques for increasing impedance bandwidth and obtaining notched bands in the proposed antenna are newer than methods mentioned in the references.

Table 2. Comparisons of the UWB Antenna to other UWB Antennas

\begin{tabular}{|c|c|c|c|c|c|}
\hline $\begin{array}{c}\text { Performance } \\
\text { compare }\end{array}$ & The Ant. & Ref. [8] & Ref.[9] & Ref. [10] & Ref. [11] \\
\hline $\begin{array}{c}\text { Dielectric } \\
\text { constant }\end{array}$ & 4.4 & 4.4 & 2.65 & 4.4 & 3.38 \\
\hline $\begin{array}{c}\text { Thickness } \\
(\mathrm{mm})\end{array}$ & 1 & 1 & 1 & 1.6 & 0.8 \\
\hline Size (mm) & $22 \times 15$ & $41 \times 34$ & $15 \times 22$ & $30 \times 26$ & $32 \times 26$ \\
\hline $\begin{array}{c}\text { Bandwidth } \\
(\mathrm{GHz})\end{array}$ & $2.6-11.4$ & $2.8-11.8$ & $2.9-12$ & $3-11$ & $2.8-11$ \\
\hline
\end{tabular}



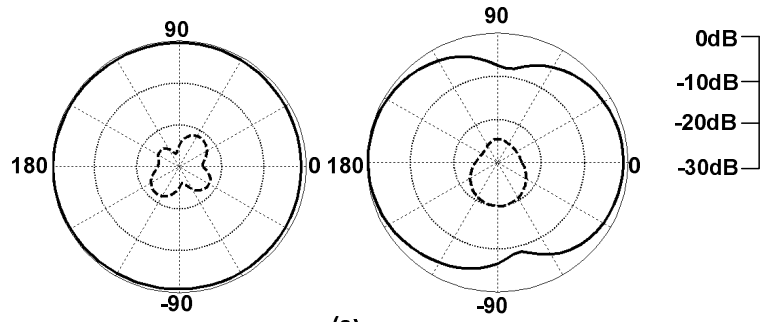

H-Plane

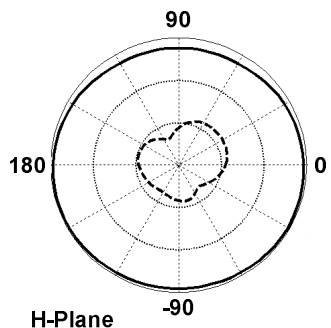

1

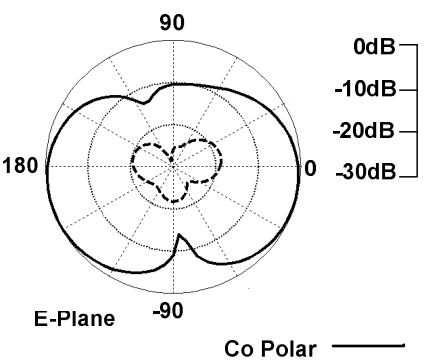

(b)

Fig. 11. Radiation patterns of the antenna at (a) 4.5 and (b) $8 \mathrm{GHz}$

\section{CONCLUSION}

In this paper, a new microstrip antenna with extended bandwidth capability for UWB applications was presented. In this design, the antenna can operate from 2.6 to $11.4 \mathrm{GHz}$ with VSWR $\leq 2$ and displays a good omnidirectional radiation pattern even at higher frequencies. The designed antenna has a small size of $15 \times 22 \mathrm{~mm}^{2}$ while showing the band rejection performance in the frequency bands of 3.2 to 4 and 5.1 to $6.1 \mathrm{GHz}$, respectively. The paper mentions to a valuable point including the use of the seventh derivative of Gaussian pulse for covering FCC mask. Good VSWR and radiation pattern characteristics are obtained in the frequency band of interest.

\section{REFERENCES}

[1] Jui-Han Lu, Chih-Hsuan Yeh, "Planar Broadband Arc-Shaped Monopole Antenna for UWB System", IEEE Transactions on Antennas and Propagation, vol. 60, no. 7, 2012, pp. 3091-3095.

[2] C.-C. Lin, Y.-C. Kan, L.-C. Kuo, and H.-R. Chuang, "A planar triangular monopole antenna for UWB communication", IEEE Microwave and Wireless Components Letters, vol. 15, no. 10, 2005, pp.624-626.

[3] C.-Y. Huang and W.-C. Hsia, "Planar elliptical antenna for ultrawideband communications", Electronics Letters, vol. 41, no. 6, 2005, pp.296-297.

[4] J. Liang, L. Guo, C. C. Chiau, X. Chen, and C. G. Parini, "Study of CPW-fed circular disc monopole antenna for ultra wide-band applications", IEE Proceedings: Microwaves, Antennas and Propagation, vol. 152, no. 6, 2005, pp. 520-526.

[5] Z. N. Chen, T. S. P. See, and X. Qing, "Small printed ultra wideband antenna with reduced ground plane effect", IEEE Transactions on Antennas and Propagation, vol.55, no.2, pp.383388, 2007.

[6] M. Mighani, M. Akbari, N. Felegari, "A Novel SWB Small Rhombic Microstrip Antenna with Parasitic Rectangle into Slot of the Feed Line", Applied Computational Electromagnetics Society (ACES) Journal, vol. 27, no. 1, pp. 74-79, January 2012.

[7] Reza Zaker, Changiz Ghobadi, Javad Nourinia, "Bandwidth Enhancement of Novel Compact Single and dual Band-Notched Printed Monopole Antenna with a Pair of L-Shaped Slots", IEEE Transactions on antennas and propagation, vol.57, no.12, December 2009.

[8] Q. X. Chu and Y. Y. Yang, "A compact ultrawideband antenna with 3.4/5.5 GHz dual band-notched characteristics," IEEE Trans. Antennas Propag., vol. 56, no. 12, pp. 3637-3644, Dec. 2008.

[9] Liu, S. Gong, Y.Xu,X. Zhang, C. Feng, and N.Qi, "Compact printed ultra-wideband monopole antenna with dual band-notched characteristics," Electron. Lett. vol. 44, no. 12, pp. 710-711, Jun. 2008.

[10] M. Abdollahvand, G. Dadashzadeh, and D. Mostafa, "Compact dual band-notched printed monopole antenna for UWB application," IEEE Antennas Wireless Propag, Lett. vol. 9, pp. 1148-1151, 2010.

[11] W. Jiang and W. Che, "A Novel UWB Antenna with Dual Notched Bands for WiMAX and WLAN Applications," IEEE Antennas Wireless Propag, Lett, vol. 11, 2012, pp. 293-296.

[12] M. Mighani, M. Akbari, N. Felegari, "A CPW Dual Band Notched UWB Antenna", Applied Computational Electromagnetics Society (ACES) Journal, vol. 27, no. 4, , April 2012, pp. 352-359.

[13] Qing-Xin Chu, and Ying-Ying Yang, "A Compact Ultrawideband Antenna With $3.4 / 5.5 \mathrm{GHz}$ Dual Band-Notched Characteristics", IEEE Transactions on Antennas and Propagation, vol. 56, no. 12, December 2008, pp. 3637 - 3644.

[14] Carla R. Medeiros, Jorge R. Costa, and Carlos A. Fernandes, "Compact Tapered Slot UWB Antenna with WLAN Band Rejection", IEEE Antennas and Wireless Propagation Letters, vol. 8, 2009, pp. 661-664.

[15] CST Microwave studio, ver. 2008. Computer simulation technology, Framingham, MA, 2008.

[16] Ansoft HFSS User's manual, Ansoft Corporation, Beta Release 11.0, April 2007.

[17] S. M. Abbas, Y. Ranga, A. K. Verma, and K. P. Esselle, “A Simple Ultra Wideband Printed Monopole Antenna With High Band Rejection and Wide Radiation Patterns," IEEE Transactions on Antennas and Propagation, vol. 62, no. 9, pp. 4816-4820, Sep. 2014. 